\title{
Malaysian University Student Learning Involvement Scale (MUSLIS): Validation of a Student Engagement Model
}

\author{
"FAUZIAH MD. JAAFAR \\ ROSNA AWANG HASHIM \\ TENGKU FAEKAH TENGKU ARIFFIN \\ Universiti Utara Malaysia \\ Corresponding author: mjfauziah@uum.edu.my*
}

\begin{abstract}
Purpose - In western countries, a model to explain student engagement in college or university has long been established. However, there is a lack of research to develop and validate a model which may help to better understand student engagement in the local university context. There is currently no established instrument to measure student engagement specifically in the Malaysian (or Asian) university context. This study was conducted to fill the gap. A measurement model on student engagement in the Malaysian university context, based on Astin's (1984) Student Involvement Theory, was developed and validated for use in the local context.
\end{abstract}

Methodology - This study uses a survey research method to test the Malaysian University Student Learning Involvement Scale (MUSLIS), a measurement model of student engagement in the local university context. The MUSLIS is a 24-item scale designed to obtain feedback on the extent of student engagement at the tertiary level in the Malaysian context. The questionnaire was distributed to 347 final year students from Universiti Utara Malaysia. The data was analysed using the SPSS software (version 16.0) to run the exploratory factor analysis (EFA) and AMOS (version 16.0) to analyse the confirmatory factor analysis (CFA).

Findings - Holistic evaluation of the model of student engagement found that the data collected acceptably fit the model. The instrument used was also found to be reliable. 
Significance - This study pioneers research in the measurement of tertiary student engagement, the first of its kind, in the Malaysian context. However, a wider sample comprising data from different universities in the country should be conducted to further confirm the usability and validity of the proposed MUSLIS. The instrument can be used in studies which seek to examine the outcomes of student involvement. In practice, the measurement of student involvement provides useful information on the extent of student participation in activities on and out of campus, whether these are academicoriented or societal activities.

Keywords: Student involvement, university, higher education, student development

\section{INTRODUCTION}

Student involvement has been found to be one of the important predictors of their academic performance and soft skill development at the tertiary level. A student who is more involved in university life would normally perform better academically and develop themselves more holistically in terms of their soft skills. Academic achievement of students in their degree programmes is not the only criterion required of them by their future employers. Studies on graduate employability have found that graduates with better soft skills are more appealing to employers (Raybould, \& Sheedy, 2005).

Numerous studies have been carried out to examine student engagement in general (Astin, 1984) or student engagement in schools (Rosna Awang Hashim \& Azlina Murad Sani, 2008; Sharifah Azizah Syed Sahil \& Rosna Awang Hashim, 2011), and student engagement in university courses (Handelsman, Briggs, Sullivan $\&$ Towler, 2005). Some of the instruments on student involvement used in previous studies have been tested for their reliability and validity. However, these instruments were mostly developed for use in the western context. They were essentially concerned with how the environment has affected student involvement in the college or university context. Thus, in this study, based on the prevalent theoretical framework of student involvement and previous related literature, we have proposed a model of student involvement, derived from the feedback obtained from the validation of our 
locally designed instrument called the Malaysian University Student Learning Involvement Scale (MUSLIS). The proposed measurement model was tested to see if there was an acceptable fit with the data collected in a local university setting, more specifically at the Universiti Utara Malaysia.

\section{LITERATURE REVIEW}

The underpinning theory that is often used in discussing student engagement is Astin's Student Involvement Theory which was first developed in 1984. The most basic tenet of this theory posits that the more physical and psychological energy that the student invests in his/her academic experience, the more engaged he/she is to his/her academic life. This theory also emphasizes that a student has high student engagement if he/she uses more energy to study, spends more time on campus, becomes actively involved in any student association, and interacts frequently with his/her faculty members and peers.

Student Involvement Theory (Astin, 1984) claims that student involvement in academic, societies or organisations at institutions of higher learning, and their involvement in communities with faculty members and peers will influence significantly the student's psychosocial development throughout his/her university or college life. The theory's five central tenets helps to identify student involvement, namely : (i) Engagement refers to investment in terms of physical and psychological energy in every aspect; (ii) Different levels of student engagement as different individuals are involved in different activities at different times; (iii) Engagement is divided into two computations which are quantitative (time allocated) and qualitative (how to focus in learning); (iv) Student engagement in a particular educational programme is measured based on quantity and quality, and (v) The effectiveness of a policy or educational practice is directly related to the increase of student engagement. Astin (1984) places great emphasis on these tenets because they serve as important guidelines when observing students in any study concerned with the construct of student engagement.

\section{Student Engagement Dimensions}

As mentioned earlier, Astin's (1984) Student Involvement Theory is the seminal work often referred to in studies related to student engagement. Based on the five tenets discussed above, Astin is of the 
view that the measurement of student involvement should include the following four important dimensions: (i) student academic engagement; (ii) student engagement with faculty members, (iii) student engagement with peers, and (iv) student engagement in communities. These four dimensions cover the basic aspects of student involvement in the university because they provide a comprehensive overview of the kind of activities students are involved in, generally in any campus. More specifically, they cover aspects such as: who they are involved with, where and when the activities occur, and the purpose of involvement. In an important sense, they underscore and attend to the essentially qualitative nature of student involvement. In addition, students' ratings of the frequency of their involvement in each aspect, would give information on the extent of their involvement in university life in a quantitative manner.

\section{Student Academic Engagement}

The concept of student academic engagement refers to the academic planning, strategies and focus that students invest in while they are on campus. They do this in order to achieve their ultimate academic goal, which for all intents and purposes is to excel in their studies.

\section{Student Engagement with Academic Staff}

\section{Student Engagement with Academic Staff}

Student engagement with academic staff refers to the interactions between student and academic staff that take place either during the lecture or outside the lecture halls, in the computer labs, during office hours, or anywhere possible. This kind of engagement is one of the keys that are related to university experience and student development itself.

Most researchers used the expression "student engagement with faculty" in previous studies (Astin, 1984, 1999; Bradley, Kish, Krudwig, Williams, \& Wooden, 2002; Norzaini Azman, Manisah Mohd Ali, Abdul Halim Tamuri \& Zalizan Mohd Jelas, 2005; Sax \& Kim, 2009). However, in this study, the expression "student engagement with academic staff" is used instead to convey the same meaning and help avoid the confusion and/or difficulty that might arise because students are not familiar with the intended meaning of the word "faculty." 


\section{Student Engagement with Peers}

Student engagement with peers refers to all student activities whereby and the student is interacting with his/her peers in carrying out the activities together. It includes such activities as working together in completing a particular project or assignment either in classrooms or outside the classrooms, working on class presentations, and using electronic media to discuss with peers.

\section{Student Engagement with the Community}

Past research (Cooper, et al., 1994; Foubert \& Grainger, 2006) employed the terms organisation and club to denote student engagement in organisations. In this research, however, the term student engagement in communities is used to encompass student engagement in campus activities, organisations, clubs and associations throughout his/her stay at an institution of higher learning.

\section{RESEARCH OBJECTIVES}

The general objective of this research is to validate a measurement model of student involvement. More specifically, the research aims:

1. To establish the reliability and validity of MUSLIS;

2. To examine the interrelationship between the factors of student engagement in order to establish discriminant validity;

3. To evaluate the goodness of fit of the MUSLIS measurement model of student engagement in relation to the data gathered from the specific local tertiary context of the present study.

\section{RESEARCH METHODOLOGY}

\section{Sample}

The target population of this study were final year students because it was assumed that after having gone through at least six or seven semesters of university life, the students should be able to provide the information related to their involvement in university life, and 
also rate their psychosocial development based on their university experience. The population size was 2231 , and according to Krejcie and Morgan's (1970) table of sample size, the sample needed for the study was approximately 331. A mixed sampling technique of stratified random sampling and systematic random sampling were used to identify the respondents for this study. In total, 370 sets of questionnaires on student engagement were distributed to students from Universiti Utara Malaysia. The overall response rate was $94.6 \%$, with 350 students returning the survey forms. After data screening, the final data set were from a total of 347 students $(\mathrm{N}=$ $347)$. Out of this number, $30.4 \%$ of them were males $(n=131)$ and $69.6 \%$ were females $(n=216)$. All of the respondents were final year students at Universiti Utara Malaysia.

\section{Measurement}

The items were constructed and developed based on Student Involvement Theory (Astin, 1984), and was adapted to suit the context of universities in Malaysia. The instrument was then named as the Malaysian University Student Learning Involvement Scale (MUSLIS), and was also translated into Bahasa Malaysia, the national language of the country. The development of the items also took into account previous studies, including studies conducted by Foubert and Grainger (2006), Handelsman, Briggs, Sullivan and Towler, (2005), and Martin, (2000). The four factors in this student engagement model were measured by a total of 24 items. Students were to rate their extent of involvement by indicating how frequent they encounter each of the conditions stated, using a 5-point likert scale, ranging from "almost never" to "always."

Student Academic Engagement was measured by five (5) items. The more highly a student rate himself/herself as academically engaged, the more committed he/she would be to academic-related activities, such as planning for the courses to be taken, giving focus to (the content of) the courses, and reading related textbooks or references for the courses. A sample item is "I plan the courses that I would take every semester".

Student Engagement with Academic Staff was measured by seven (7) items. The higher the students scored for this dimension, the more frequent they communicated and discussed with academic staff their studies, coursework, academic performance and career paths. A sample item is "I discuss my grades and assignments with my lecturer". 
Student Engagement with Peers was measured by six (6) items. If a student rated himself/ herself as highly engaged with his/her peers, it would mean that he/she frequently communicated, discussed and collaborated with his/her friends in the university, especially in carrying out academic-related tasks. A sample item is "I collaborate with other students to do projects or assignments".

Student Engagement with the Community was measured by six (6) items. A student who was rated highly on his/her engagement in university would be someone who was actively involved in societal or organizational programmes, including community work or service. Students who were highly engaged in communities were those who normally displayed leadership traits. A sample item is "I'm active in the organizational or community college"

\section{Data Analysis}

Data analysis involved an examination of the instrument's reliability through measures of internal consistency and Cronbach's Alpha coefficients. Besides that, in order to establish the underlying structure of the measurement used, the data were subjected to an exploratory factor analysis, using SPSS version 16.0. In the exploratory factor analysis, maximum likelihood and direct oblimin rotation were chosen as the extraction method and rotation method, respectively (Bryne, 2005).

Finally, the measurement model was tested via confirmatory factory analysis, using AMOS version 16.0. This analysis served to validate that the model developed by the researchers was appropriate with the data collected.

\section{FINDINGS OF THE RESEARCH}

Cronbach's alpha coefficient values for each dimension of student engagement factor are as displayed in Table 1. The range of the Cronbach's alpha coefficient values are between .73 (for the student engagement with peers construct) and .90 (for the student engagement in communities construct). The alpha value between .60 and .70 are suggested as the lowest acceptable value to determine the instrument's reliability (Hair, Black, Babin, Anderson \& Tatham, 2006). Therefore, based on the analysis results discussed above, the instrument used in this study can be considered as a reliable measurement in terms of its internal consistency. 
Table 1

Reliability of the Mean, Standard Deviation for Each Student Engagement Factor

\begin{tabular}{lccc}
\hline Factors of Student Engagement & Mean & $\begin{array}{c}\text { Standard } \\
\text { Deviation }\end{array}$ & $\begin{array}{c}\text { Cronbach's } \\
\text { Alpha }\end{array}$ \\
\hline 1. Academic Engagement & 4.17 & .52. & .79. \\
2. Engagement with Academic Staff & 3.05 & .69 & .79 \\
3. Engagement with Peers & 4.19 & .52 & .73 \\
4. Engagement in Communities & 3.44 & .82 & .90 \\
\hline
\end{tabular}

Results of the exploratory factor analysis, indicated that the items loaded fairly strongly on four factors, except for two items, which were later dropped, leaving the remaining items to number 22 . The outcome of the exploratory factor analysis revealed that the two items excluded were supposed to load onto the dimension of Engagement with Peers (EP). However, these two items, labelled as EP5and EP6, had factor loadings lower than .32. The exclusion of the items were made based on the suggestions made by Tabachnik and Fidell (2007), who advised that the threshold for factor loading is .32, for an item to be considered as a good item in measuring a construct. Also, revisions were made to ensure that the exclusion of these items did not affect the operational definition given on the Student Engagement with Peer dimension. Table 2 shows the results of the exploratory factor analysis rerun after the exclusion of the two items.

Table 2

Results of the Exploratory Factor Analysis for Student Engagement Constructs

\begin{tabular}{lcccc}
\hline \multirow{2}{*}{ Item } & \multicolumn{4}{c}{ Factor Loadings } \\
\cline { 2 - 5 } & Factor 1 & Factor 2 & Factor 3 & Factor 4 \\
\hline EA 3 & .69 & & & \\
EA 5 & .65 & & & \\
EA 4 & .64 & & & \\
EA 2 & .58 & & & \\
\hline
\end{tabular}




\begin{tabular}{|c|c|c|c|c|}
\hline \multirow{2}{*}{ Item } & \multicolumn{4}{|c|}{ Factor Loadings } \\
\hline & Factor 1 & Factor 2 & Factor 3 & Factor 4 \\
\hline EA 1 & .47 & & & \\
\hline EA 6 & .46 & & & \\
\hline EA 7 & .32 & & & \\
\hline EP 2 & & .94 & & \\
\hline EP 1 & & .77 & & \\
\hline EP 3 & & .53 & & \\
\hline EP 4 & & .34 & & \\
\hline EC 2 & & & .87 & \\
\hline EC 1 & & & .84 & \\
\hline EC 4 & & & .80 & \\
\hline EC 5 & & & .75 & \\
\hline EC 6 & & & .73 & \\
\hline EC 3 & & & .61 & \\
\hline AE 3 & & & & .73 \\
\hline $\mathrm{AE} 2$ & & & & .65 \\
\hline AE 5 & & & & .64 \\
\hline AE 1 & & & & .59 \\
\hline $\mathrm{AE} 4$ & & & & .58 \\
\hline
\end{tabular}

Note: $\mathrm{AE}=$ Student Academic Engagement; EA = Student Engagement with Academic Staff; EP = Student Engagement with Peers; and, EC = Student Engagement with the Community. Only loadings of more than .32 are shown in this table.

Before subjecting the data to a confirmatory factor analysis, the researchers decided to parcel all items accordingly, based on their loading values. Items are usually bundled into parcels so as to avoid non-convergence during the estimation process. Table 3 shows the combining of items for Student Engagement constructs based on the loading values in each factor, a technique which is suitable for items which have a wide range of loading values. The parcelled items would become more stable when the items which loaded more strongly are combined with those which loaded more weakly (Bandalos, 2002). All 22 items that measured Student Involvement were parcelled with the four dimensions of student engagement, based on Astin's Student Involvement Theory (Astin, 1984). The 
four dimensions referred to are Student Academic Engagement, Student Engagement with Academic Staff, Student Engagement with Peers and Student Engagement in Communities.

Table 3

Parcelling of Items According to Factor Loading Values

\begin{tabular}{llcc}
\hline \multicolumn{1}{c}{ Construct } & Factor/ Dimensions & Parcel & Item \\
\hline Student & Student Academic Engagement & SAE1 & AE5 \\
Engagement & & SAE2 & AE3 \\
& & & AE2 \\
& & AE4 \\
& Student Engagement with & SEA1 & EA7 \\
& Academic Staff & & EA3 \\
& & SEA2 & EA1 \\
& & EA4 \\
& & SEA3 & EA2 \\
& & EA6 \\
& Student Engagement with Peers & SEP1 & EP4 \\
& & EP2 \\
& SEP2 & EP3 \\
& & EP1 \\
& Student Engagement in & EC3 \\
& & & EC2 \\
& & SEC2 & EC1 \\
& & EC4 \\
& & & ECC3 \\
& & & EC6 \\
\hline
\end{tabular}

Note: SAE = Student Academic Engagement; SEA = Student Engagement with Academic Staff; SEP = Student Engagement with Peers; and, SEC = Student Engagement with the Community.

The parcelled items were then submitted to another round of exploratory factor analysis with maximum likelihood and direct oblimin method, to ensure that all parcels loaded into the right factors. Apart from this, the Kaiser Meyer Olkin (KMO) value of .79, indicated that the sample was adequate for exploratory factor analysis (Table 4). Bartlett's test also showed that the value of 1260.22 was significant at $\mathrm{p}<.05$, indicating that the item correlation matrix does not indicate an identity matrix (Hair et al. 2006). Table 4 shows the results of the exploratory factor analysis for the parcelled items. 
Table 4

Result of the Exploratory Factor Analysis for Student Engagement Factors (based on item parcelling)

Item Parcelling

\begin{tabular}{lr} 
& Factor \\
\hline SEC2 & .92 \\
SEC1 & .87 \\
SEC3 & .73
\end{tabular}

SAE1

SAE2

SEA1

SEA3

SEA2

SEP2

SEP1

73

\section{Factors}

Factor 1 Factor 2 Factor 3 Factor 4
.94

.68

\begin{tabular}{lrrrr}
\hline Total of Eigen Values & 6.38 & 3.06 & 2.01 & 1.59 \\
Percentage of variance explained & 26.59 & 12.74 & 8.38 & 6.63 \\
KMO & .79 & & & \\
Bartlett's test of sphericity* & $* 3380.90$ & & \\
df & 276 & & \\
Total of Variance explained & 54.33 \\
*p<.O & \\
Note: SAE = Student Academic Engagement; SEA = Student Engagement with \\
Academic Staff; SEP = Student Engagement with Peers; and, SEC = Student \\
Engagement with the Community. Only loadings of >.32 are shown.
\end{tabular}

The next step of the validation process was the evaluation of the measurement model, by examining the fit indexes in a holistic manner. The model exhibits acceptable fit with the data with the values of $\chi 2 / \mathrm{df}=1.65$ (less than 3.0), RMSEA $=.06$ (less than .08 ), $\mathrm{SRMR}=.04$ (less than .08 ), TLI $=.97$ and $\mathrm{CFI}=.98$ (greater than .90) (refer to Diagram 1). The disattenuated correlation values between the three constructs, with the lowest value of $\mathrm{r}=0.18, \mathrm{t}=$ $2.87, \mathrm{p}<.01$ and the highest value of $\mathrm{r}=0.52, \mathrm{t}=6.93, \mathrm{p}<.01$, supports the discriminant validity. John \& Benet-Martinez (2000) argue that the discriminant validity is achieved when the value of correlation is less than $\mathrm{r}=.90$. The range for loading factor for all parcelled items is between $\beta=.71$ and $\beta=.89$, superseding the cut-off value of 0.32 for the establishment of convergent validity. 


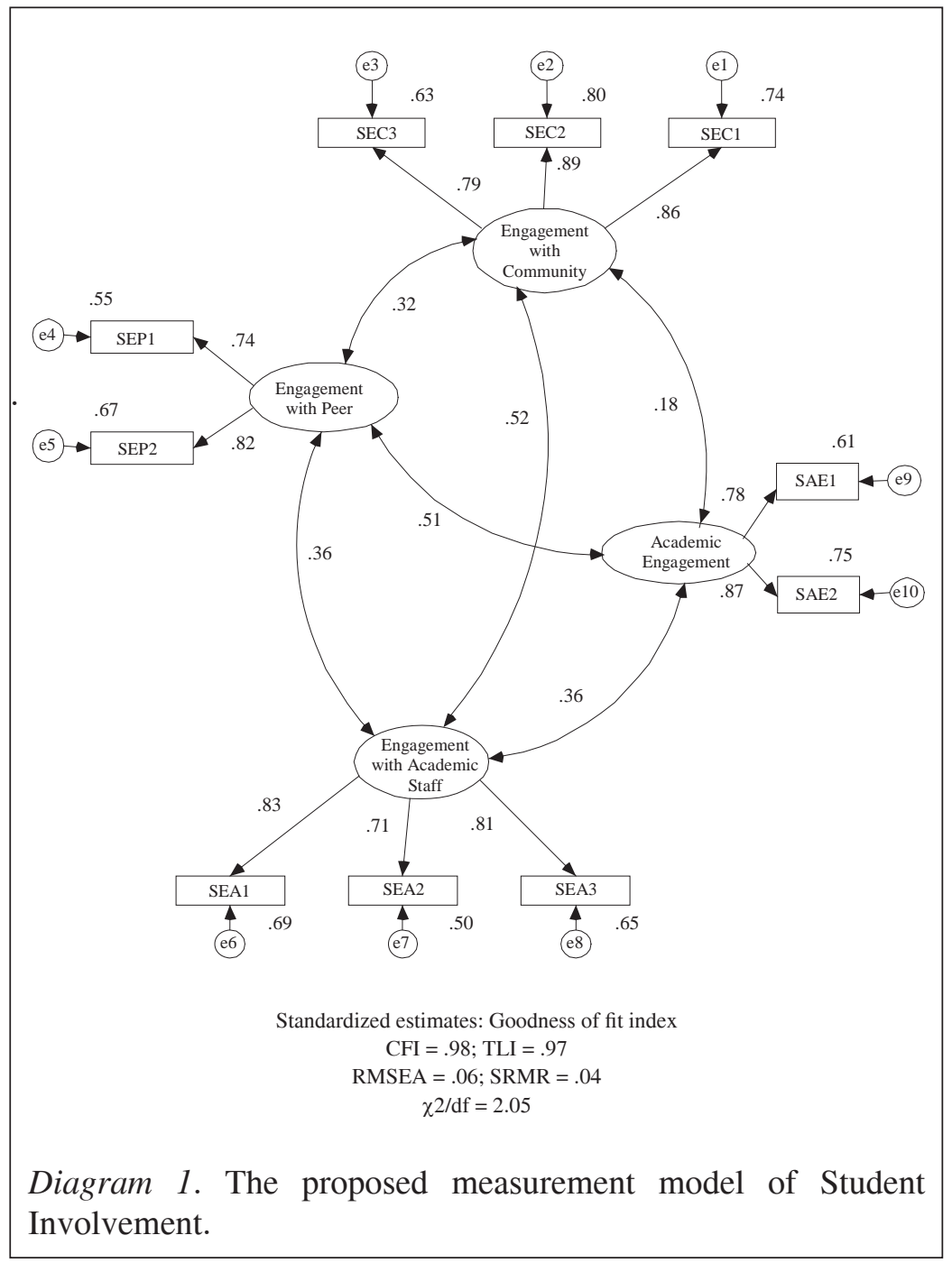

Note: SAE = Student Academic Engagement; SEA = Student Engagement with Academic Staff; SEP = Student Engagement with Peers; and, SEC = Student Engagement with the Community

\section{DISCUSSION}

Student engagement in university life has, on the whole, always been a bone of contention in the on-going debates on student performance. Student engagement has also been seen as an important predictor of student performance or success at university or college. The items 
for measuring the Student Involvement construct developed by the researchers were based on the Student Involvement Theory of Astin (1984) and on other previous studies, in particular, those by Foubert and Grainger (2006), Handelsman et al. (2005), and Martin (2000). This instrument, which was designed to measure student involvement in the Malaysian university context, was found to be a reliable instrument and could be used in future studies, especially in the local university context and perhaps, also in other Asian university contexts. The exploratory factor analysis and confirmatory factor analysis demonstrate that all the parcelled items loaded in the expected factors, namely student academic engagement, student engagement with academic staff, student engagement with peers, and student engagement with the community. The measurement model proposed by the researchers in the current study was found to be an acceptably fit model too, thus lending further evidence for discriminant convergence, and on the whole, the construct validity of the instrument.

In this study, student academic engagement refers to their commitment in planning the structure of their programme, trying to schedule this in a manner that can enhance their academic achievement. Other than that, students take their academic work seriously by reading the materials relevant to the courses that they are undertaking and also paying attention to the courses that they are studying for the semester. Students are engaged with the academic staff by doing activities such as discussing assignments or projects, discussing about their academic progress and talking about their career plans with the relevant lecturers, most probably those who are teaching the respective courses which the students are taking. Normally, students who are engaged with their lecturers will also try to get feedback on how well they are doing in the courses, either verbally or in the written mode. Their means of communication can either be through face-to-face or via electronic mails.

Similarly, Student Engagement with Peers is also made possible either via face-to-face or online. Now that there is a worldwide trend of using social media as a communication platform, students are more flexible when it comes to keeping in touch with their peers. However, students in this study did agree that they were not only involved with their friends for social purposes. More importantly, in the university context, the respondents pointed out that their involvement with peers included some academic agenda. For example, they sat together with peers to discuss their assignments or project, or even to share their experiences about the 
courses that they were taking. As expected of students in a multiracial country such as in Malaysia, the students were found to have had experience collaborating with students of other races. In terms of Student Engagement with the Community, the study also found that this factor was also relevant in the context of university student involvement in this country. Students were involved with the community on campus or outside of campus by doing activities especially when they were already members of societies, clubs or organizations within campus. University students were given the opportunity to be actively involved in community services through the activities of these diverse varieties of clubs, societies and organisations.

\section{CONCLUSION AND IMPLICATIONS}

In sum, this study provides strong empirical support for the use of the MUSLIS instrument in measuring student engagement in the context of one of the local public universities in Malaysia. The structure of the Student Involvement Model proposed in this research is similar to that of the Student Engagement Model of Astin (1984). This is because all the four dimensions of student engagement proposed by Astin, also emerged in the data obtained from students in this local university context. However, more extensive studies covering a wider and more diverse student population from other local public universities are needed to further validate the instrument and demonstrate its robustness. Besides that, future studies should also utilize the instrument in research that examines the relationship between student involvement and its outcomes, such as student psychosocial development. In practice, the information gathered through a such a survey, where it is possible to measure student involvement in the university context, will definitely be useful for understanding the kind of activities that students are involved with, and how these activities can enhance student academic and selfdevelopment, thus providing the right preparation for the job market of the future.

\section{REFERENCES}

Astin, A. W. (1999). Student involvement: A developmental theory for higher education. Journal of College Student Development, 40(5), 518-529. 
Astin, A. W. (1984). Student involvement: A developmental theory for higher education. Journal of College Student Personnel, 25, 297-308.

Bandalos, (2002). The effects of item parceling on goodness-of-fit and parameter estimate bias in structural equation modeling. Structural Equation Modeling, 9(1), 78-102.

Bradley, C., Kish, K. A., Krudwig, A. M., Williams, T., \& Wooden, O. S. (2002). Predicting faculty-student interaction: An analysis of new student expectations. Journal of the Indiana University Student Personnel Association, 72-85.

Bryne, B. (2005). Factor analytic models: Viewing structure of an assessment instrument from three different perspectives. Journal of Personality Assessment, 85, 17-32.

Cooper, D. L., Healy, M. A., \& Simson, J. (1994). Student development through involvement: Specific changes over time. Journal of College Student Development, 35, 98-102.

Foubert, J. D., \& Grainger, L. U. (2006). Effects of involvement in clubs and organizations on the psychosocial development of first year and senior college students. NASPA Journal, 43(1), 166-182.

Hair, J. F. Jr., Black, W. C., Babin, B. J. Anderson, R. E., \& Tatham, R. L. (2006). Multivariate data analysis (6th ed). New Jersey: Prentice Hall.

Handelsman, M. M., Briggs, W. L., Sullivan, N., \& Towler, A. (2005). A measure of college student course engagement. The Journal of Educational Research, 98(3), 184-191.

John, O.P., \& Benet-Martinez, V. (2000). Measurement, scale construction, and reliability. In H.T. Reis \& C. M. Judd (Eds.), Handbook of research methods in social and personality psychology (pp. 339-369). New York, NY: Cambridge University Press.

Krejcie, R. V., \& Morgan, D. W. (1970). Determining sample size for research activities. Educational and Psychological Measurement, 30, 607-610.

Martin, L. M. (2000). The relationship of college experiences to psychosocial outcomes in students. Journal of College Student Development, 41, 294-303.

Norzaini Azman, Manisah Mohd Ali, Abdul Halim Tamuri, \& Zalizan Mohd Jelas (2005). Effective higher education practices - A survey of student engagement. Malaysian Journal of Learning \& Instruction, 2, 95-119. 
Raybould, J., \& Sheedy, V. (2005). Are graduates equipped with the right skills in the employability stakes? Industrial and Commercial Training, 37(5), 259-263.

Rosna Awang Hashim \& Azlina Murad Sani. (2008). A confirmatory factor analysis of a newly integrated multidimensional school engagement scale. Malaysian Journal of Learning \& Instruction, 5, 21-40.

Sax, L. J., \& Kim, Y. K. (2009). Student-faculty interaction in research universities: differences by student gender, race, social class, and first generation status. Research High Education, 50, 437-459.

Sharifah Azizah Syed Sahil \& Rosna Awang Hashim (2011). The role of social support in promoting Adolescents' classroom cognitive engagement through academic self efficacy. Malaysian Journal of Learning \& Instruction, 8, 49-69.

Tabachinick, B. G., \& Fidell, L. S. (2007). Using multivariate statistics (5th ed.). Boston: Pearson Education, Inc. Wachs, P.M., \& Cooper, D. L. (2002). Validating the student developmental task and lifestyle assessment: A longitudinal study. Journal of College Student Development, 43(1), 124129. 